\title{
Early Reading for Young Deaf and Hard of Hearing Children: Alternative Frameworks
}

\author{
Jean F. Andrews', Beth Hamilton1, Kim Misener Dunn'2,3, M. Diane Clark1 ${ }^{*}$ \\ ${ }^{1}$ Lamar University, Beaumont, USA \\ ${ }^{2}$ Gallaudet University, Washington DC, USA \\ ${ }^{3}$ Clemson University, Clemson, USA \\ Email: *mclark22@lamar.edu
}

Received 28 February 2016; accepted 11 April 2016; published 14 April 2016

Copyright (C) 2016 by authors and Scientific Research Publishing Inc.

This work is licensed under the Creative Commons Attribution International License (CC BY). http://creativecommons.org/licenses/by/4.0/

(c) (i) Open Access

\begin{abstract}
Deaf children can develop reading skills by using a visual language to bridge meaning to English print without the use of English auditory phonology. To this end, five deafcentric frameworks are described that take into account the use of visual language and visual learning, as well as the use of deaf cultural role models in the teaching of reading. Moving away from the deficit model, these frameworks focus on Deaf ${ }^{1}$ students in the act of reading in order to document their actual behaviors using a bilingual American Sign Language/English philosophy. These five models suggest that there is more involved in reading than simply bottom-up code-based strategies based on spoken language. Multiple pathways are recommended, based on the work of Treisman, and his idea of "fault tolerant" approaches, which permit and encourage multiple pathways for deaf readers.
\end{abstract}

\section{Keywords}

Deaf, Top-Down Reading Strategies, ASL/English Bilingual Approaches

\section{A New Lens to Look at Deaf Readers}

A deaf doctoral student commented, "How many more English tests do hearing people have to give deaf children before they know deaf students have English deficiencies? Don’t we already know this?” Conventional reading research in deaf education has taken the stance of a deficit approach, as it repeatedly catalogues the deficits in English phonological, vocabulary, and syntax typically found with deaf readers. As this deaf graduate student noted, how many more studies do we need? Challenged by her question and with her joining us in a

"Corresponding author.

${ }^{1}$ The use of a D in the word Deaf refers to people who use sign language, identify with the Deaf culture, and interact within the Deaf community.

How to cite this paper: Andrews, J. F., Hamilton, B., Dunn, K. M., \& Clark, M. D. (2016). Early Reading for Young Deaf and Hard of Hearing Children: Alternative Frameworks. Psychology, 7, 510-522. http://dx.doi.org/10.4236/psych.2016.74052 
deaf-hearing partnership, we propose a different approach, one that looks at deaf children's reading problems through the lens of critical pedagogy, and concludes with the notion of building fault tolerant systems that analyze systemic failures.

A recent study by Cupples, Ching, Crowe, Day, and Seeto (2014) evaluating deaf children using spoken language led us to conduct a review of alternative frameworks for early reading, created for signing deaf students. These frameworks move away from a deficit model, but may not critically assess or propose new solutions for all deaf children. These alternative frameworks focus on deaf students in the act of reading, and document their actual reading behaviors to build more effective strategies. These frameworks were developed so that deaf readers would be successful, using more top-down strategies rather than focusing on bottom-up strategies. Given that there are multiple pathways which can lead to successful reading for deaf bilinguals (Allen, Letteri, Choi, \& Dang, 2014; Andrews \& Mason, 1986; Freel et al., 2011), we conclude this line of reasoning with a challenge to develop fault tolerant approaches that explore, permit, and encourage multiple pathways for all deaf readers to become successful. These paths tend to challenge and avoid bottom-up drill as the most efficacious strategy for learning to read.

Overall, classroom observations and research on deaf readers find that even young deaf children, with limited proficiencies in both American Sign Language (ASL) and English, when learning to read take advantage of signing and fingerspelling (Andrews \& Mason, 1986; Andrews, 2012). These findings are in contrast to traditional approaches to early reading instruction and frameworks that have been designed for deaf students. The proposed alternative frameworks involve visual language, including ASL, printed texts, and visual processing. Visual processing strategies focus on visual learning, where learning is processed through the eye and can include visual engagement strategies such as visual attention, gaze behaviors, visual joint attention (see reviews in Baker, 2011; Hirshorn, 2011; Lieberman, Hatrak, \& Mayberry, 2011), as well as the use of pictures, illustration, drawings, print, movies, and visual media (Kuntze, Golos, \& Enns, 2014).

\section{The Big Picture}

Despite decades of teaching and research, the basic process of how deaf children transform print into thought without full access to language is not fully understood (see Marschark \& Everhart (1997) for a treatise on the relation between language and thought). Like the Cupples et al. (2014) perspective, some researchers believe that comprehending the auditory phonological structure of words (Geers \& Hayes, 2011; Luckner, Sebald, Cooney, Young, \& Muir, 2005; Trezek \& Mayer, 2015; Paul, Wang, Trezek, \& Luckner, 2009) is a key factor in deaf children's early literacy difficulties. This approach has gained momentum and has been applied to early literacy learning as more deaf and hard of hearing children have access to the phonology of English with cochlear implants or digital hearing aids (see for example, Johnson \& Goswami, 2010; Montag, AuBuchon, Pisoni, \& Kronenberger, 2014). However, Mayberry, del Giudice and Lieberman (2011) counter-argue that language, not phonological awareness, is the key variable to reading for deaf students. They provided a meta-analysis of studies that showed that phonological awareness accounted for $11 \%$ of the variance, with a greater percentage of the variance being explained by reading comprehension. Importantly, 35\% of the variance was explained by overall language proficiency. Similarly, Geers and Hayes (2011) noted that deaf children with CIs had higher performance on more global literacy measures than on phonological processing tasks, suggesting to them that visual processing strategies provided alternative routes to reading. Moreover, Clark, Gilbert and Anderson (2011) found the phonological awareness was not related to reading skills; some participants had near perfect phonology and weak reading skills while others were reading at the post-secondary levels with almost no phonological skills. Given this findings as well as other published work (e.g., Freel et al., 2011; Miller \& Clark, 2011), we do not fully understand whether phonological skills are acquired after the development of reading skills, in contrast to the idea that phonological skills are precursors to becoming a skilled reader.

What we do know is that compared to hearing children, it takes deaf children longer to learn to read, often three to four years and sometimes even longer (Hoffmeister \& Caldwell-Harris, 2014), with many youth plateauing at the fourth grade level even after nine or more years of education (Traxler, 2000). Such low reading achievement levels are found worldwide with deaf children learning to read both alphabetic and logographic scripts (Liu, Liu, \& Andrews, 2014; Qi \& Mitchell, 2011; Wang, Paul, \& Lee, 2010). We also know that many deaf children do learn to read early, particularly those who have deaf parents (Lieberman, Hatrak, \& Mayberry, 2011; Herbold, 2008). The aspects of reading that we do understand are related to observable factors such as the demographic characteristics of deaf children, including their early access to spoken and sign languages, as well 
as supportive parents. Still there is ample documentation on the challenges deaf children face with the linguistic features of texts at the word, phrase, clause, sentences, and discourse levels (Paul \& Wang, 2012).

\subsection{Reading Difficulties for Deaf Children}

As deaf children progress in school, they often have difficulty with comprehending morphemes (Nielsen, Luetke, \& Stryker, 2011), and acquiring and comprehending vocabulary (particularly multiple meaning words (see reviews in Paul et al., 2009). In addition, there are problems in comprehension including; figurative language (Rittenhouse \& Stearns, 1990), verb particles (Payne \& Quigley, 1987), syntax (Kelly, 1996) and accessing world knowledge (Convertino et al., 2014). Importantly, as these types of linguistic and cognitive structures are often the foundation of children's books, the problems make reading complicated for these deaf children. For example, Sugiura (2012) used Family Circle comic strips to test elementary aged deaf children's reading skills. These children were reading below the second grade level and were found to have difficulty understanding the meaning of punctuation marks, such as quotation marks in dialogue, verb contractions, ellipses, and exclamation marks. These types of findings highlight the cognitive, grammatical and reading fluency difficulties typical of many deaf readers.

There are several other issues that often are problematic in deaf children's reading development. Effective eye gaze synchrony (Clark et al., 2015), the development of joint attention strategies (Lieberman et al., 2011), and parent/child storybook reading (Andrews \& Zmijewski, 1997; Berke, 2013; Lartz, 1999) are often missing in hearing families that are not using a visual language. These issues mentioned above often limit parent involvement in literacy activities in the home. These gaps in early interactions between a child and their parents with print and books can therefore delay and limit literacy outcomes (Andrews \& Mason, 1986; Andrews \& Zmijewski, 1997; Bailes, Erting, Erting, \& Thumann-Prezioso, 2009; Berke, 2013; Watson \& Swanwick, 2008; Williams, 2004). All of these cognitive and linguistic developmental issues create problems for many deaf children as they learn to read.

\subsection{Factors That Impact Literacy and Deaf Children}

The key factor for deaf child's reading is early and full language access, whether the language is auditory or visual, (Goldin-Meadow \& Mayberry, 2001; Mayberry, Lock, \& Kazmi, 2002; Mayberry et al., 2011; Pénicaud et al., 2013). Limiting the deaf child to only auditory pathways for language learning is risky, even with newer auditory technologies, such as digital hearing aids and cochlear implants, as they may not provide full access to auditory language. Therefore, these children need exposure to language models in both visual and auditory modalities from the time hearing loss is detected, to take full advantage of the sensitive period for language learning (see reviews in Humphries et al., 2014; Kuhl \& Rivera-Gaxiola, 2008; Kushalnagar et al., 2010).

ASL is a natural language, which has all the properties of spoken languages, with fundamentally different linguistic and grammatical structures (Andrews, Leigh, \& Weiner, 2004). Moreover, ASL occurs in a different modality (Traxler, 2012). Despite these differences, the brain does not differentiate between signed languages or spoken languages and children acquire either, or both, if the languages are provided in the environment (Petitto, 2009; Petitto et al., 2012). Given that 95\% of all deaf children are born to hearing parents, access to visual language is often not provided (Andrews, Leigh, \& Weiner, 2004). This choice of only presenting spoken language to a deaf child may not provide sufficient linguistic input to allow typical cortical development (Pénicaud et al., 2013) or the acquisition of typical linguistic milestones (Andrews, Logan, \& Phelan, 2008). Recent research on bimodal bilingual children (those who had exposure to both spoken and sign languages) with cochlear implants found that exposure to early sign language lead to increases in spoken language skills when compared to cochlear implant children without sign exposure (Hassanzadel, 2012).

\subsection{Reading Models for Deaf Children}

Curriculums developed to teach hearing children to read have been used to teach deaf children to read and most of them focus on auditory phonology. Stanovich (2000) focuses on reading problems related to phonological sensitivity in hearing individuals. His theory is used in the Qualitative Similarity Hypothesis (see Paul, Wang, \& Williams, 2013). The Simple View of Reading emphasizes both decoding and comprehension to explain reading difficulties (Gough \& Tunmer, 1986); these ideas can be seen for deaf readers in Easterbrooks et al. (2015). Others have utilized Mason's top-down model, which underscores the importance of reading whole stories to 
preliterate children to help them make connections to early reading (Mason, 1980) and is found in the work of Andrews and her colleagues (Andrews, 2012; Andrews \& Mason, 1986; Andrews, Winograd, \& Deville, 1994). Still others focus on the bilingual acquisition of ASL and English (Allen, Letteri, Choi, \& Dang, 2014; Hoffmeister \& Caldwell-Harris, 2014; Kuntz, Golos, \& Enns, 2014; McQuarrie \& Parrila, 2014; Supalla, Wix, \& McKee, 2001) rather than applying traditional reading models developed for hearing children. These theoretical perspectives are expanded below.

\subsection{Qualitative Similarity Hypothesis}

A view articulated by Paul (2013), as well as Trezek and Mayer (2015), labeled the Qualitative Similarity Hypotheses $(Q S H)$, is that deaf children go through the same process as their hearing peers in learning to read, even if they are delayed in their reading milestones. Here, visual and auditory tools developed by educators for hearing children are added to provide deaf children access to auditory phonemic awareness and the alphabetic principle (Paul \& Wang, 2012). One augmentative technique is speech reading, but only 30\% of English phonemes can be visually distinguished on the lips (Andrews et al., 2004) making the technique ineffective for full comprehension. Another tool is that of the use of articulatory feedback (Seifert et al., 2002), which is also limited by the amount of speech the child can hear, with or without cochlear implants and/or digital hearing aids. To overcome these limitations, Cued Speech was developed (Cornett, 1967) and consists of eight hand shapes or cues (representing consonants) at four different locations around the mouth (representing vowel sounds). These cues and mouth positions are used in combination with residual hearing and the visual information from speech reading to make the phonemes of English visible to the deaf child. A more recent system, called Visual Phonics (International Communication Learning Institute, 1996), is being used in deaf education and consists of 46 manual representations or hand gestures, with the 45 written symbols that correspond to the 45 phonemes of English, with a 46th hand gesture used to indicate the silent "e". Each mouth movement is paired with a hand gesture to represent a single phoneme of English (Paul \& Wang, 2012). These visual markings are hypothesized to make English phonology available to deaf children, and allow them to develop reading skills in similar ways to their hearing peers, but often at a delayed rate.

Easterbrooks and her colleagues (Easterbrooks et al., 2015) also believe that auditory phonological awareness is important and follow the Simple View of Reading (SVR) (Gough \& Tunmer, 1986), which emphasizes that decoding skills and oral language development are needed for reading to take place. Here the use of fingerspelling was included in the model, but only in relationship to mapping onto the letters of the alphabet.

In sum, the QSH researchers (Easterbrooks et al., 2015; LaSasso \& Crain, 2015; Paul, 2013; Trezek \& Mayer, 2015) collectively suggest that both language-related and auditory code-related skills are needed for reading development. Each propose that proficiency in face-to-face communication of the target language (English), including its phonological aspects (whether presented auditorily or visually) are critical for the literacy development of deaf children.

\subsection{Visual Language Learning \& Mapping Sign/Fingerspelling to Print}

Pattern recognition of the smallest units of language is a skill that all language learners must learn, whether these be auditory sounds or units that are represented visually and tactilely through speechreading, articulatory feedback, Visual Phonics, Cued Speech, signs, fingerspelling or written letters (Andrews \& Wang, 2015). In contrast to the above researchers who focus on auditory phonology, some researchers connect meaning to print by using visual phonology and sign orthography. This strategy goes directly from print to meaning (Allen et al., 2014). Here visual phonology (or alternative visually based ASL phonology or visual sign phonology) is the mechanism used to learn to read. This visual segmentation provides the prosodic and suprasegmental structure of signs, signed sentences, fingerspelling, and the orthographic patterns of letters. Allen (2015) studied 251 deaf children, ages 3 to 7 who had severe to profound hearing losses, examining the impact of early visual language on early literacy, cognition, and social adjustment. He found that when fingerspelling skills were controlled for, ASL showed an independent effect on letter knowledge. Here, ASL skills were interpreted as being derived from a visually based phonological process that transfers to the learning of letters and an orthographically based system of sub-lexical units that can combine to form words and can occur independently of letter-sound knowledge as well as fingerspelling. Therefore, both ASL receptive skills and fingerspelling skills were strongly and independently related to children's alphabetic knowledge (see Figure 1). Allen and colleagues concluded that reading 


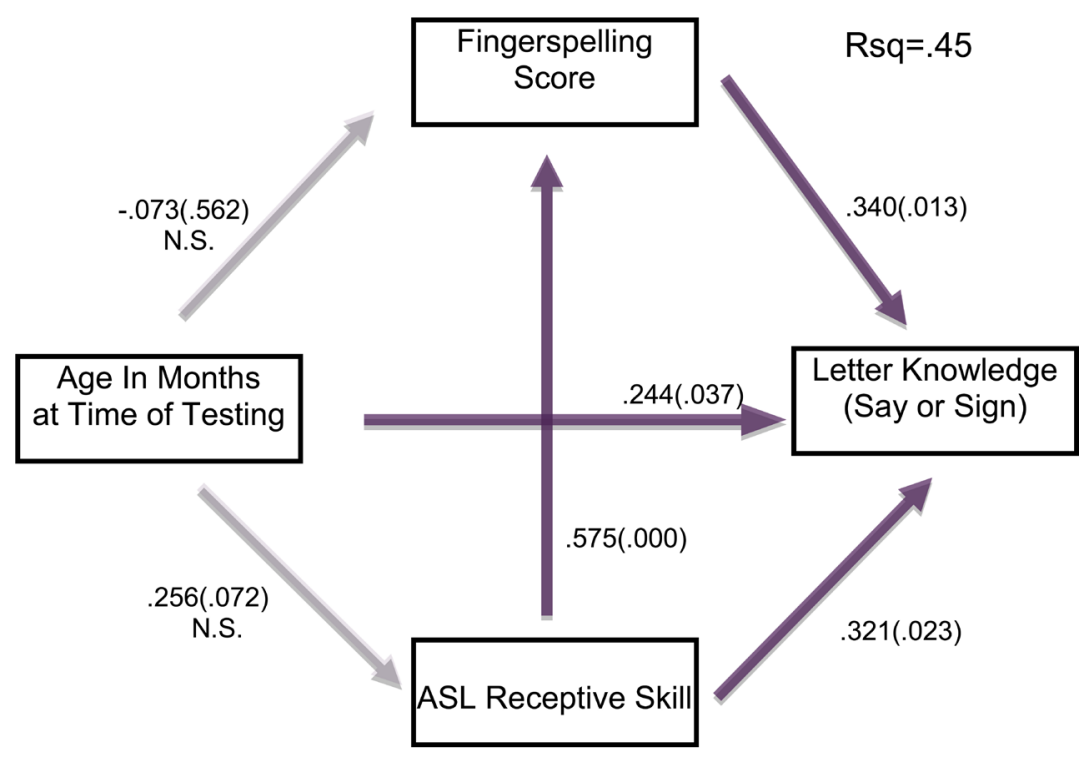

Standardized Path Coefficients using Recursive Linear Regression Path Model (significance levels in parentheses)

Figure 1. Path model showing impacts of age, ASL Receptive Skill, and Fingerspelling Skill on letter knowledge using a say or sign task.

can be qualitatively similar to hearing children, if it is presented in forms that are "modality independent", i.e., visually (Allen et al., 2014: p. 355). In addition Allen et al. (2015) found that among the three, four, and five years old within their database who had parents who used ASL, these children had the highest levels of letter knowledge. This effect to a lesser extent was also found with children whose parents were only beginning to learn to sign. Children whose parents used only spoken language had the lowest levels on pre-literacy measures.

Another model based on visual language and visual learning is called the Functional Equivalency Model (McQuarrie \& Parilla, 2014). This model asserts that there are some aspects of reading for deaf people that are similar to that of hearing readers. However, their work suggests that deaf readers "crack the orthographic code" in fundamentally different ways than do their hearing peers. Their findings show that deaf readers were insensitive to the auditory phonological structure of words at the syllabic, rhyming, and phonemic levels. Similar to the model proposed by Allen et al. (2014), these authors concluded that factors of sign language and print orthography contribute to the reading processes of deaf children, and replace auditory phonology.

Related to the visual nature of the models of Allen et al. (2014) and McQuarrie and Parilla (2014), other work shows that visual pattern recognition of larger chunks of letters is also important. For example, deaf children who learn the print letter patterns of morphemes, which are highly regular, use these patterns as another visual learning strategy when learning to read (Nunes \& Bryant, 2006). They used materials based on morpheme teaching, linking their work to that with hearing children. Numes and Bryant's participants, after given morpheme instruction, had significantly higher understanding of using suffixes in spelling, word reading, reading comprehension and writing skills. Similar findings by Nielsen, Luetke, and Stryker (2011) show the importance of morphemic awareness for supporting reading development for deaf children.

\subsection{Three-Stage Descriptive Model}

Hoffmeister and Caldwell-Harris (2014) propose another model grounded in visual language and visual learning. In their model, deaf children can become skilled readers, through reading and writing of English print. They state that the phonology of English is not necessary. The authors emphasize that is it not deafness per se that causes reading difficulties, but a lack of full access to a visual language. This lack of access to visual language causes the inherent difficulties deaf children have in acquiring language when they cannot practice it outside of the school activities of reading and writing. In this model, there are three stages of learning that represent successive, conceptual insights for deaf children learning their second language (English) through print. In the first 
stage of learning to read, deaf children learn how to map translations of familiar signs and sign phrases to print at the word and phrase level. In stage 2, the children progress to mapping signs to words and sentences, including idioms, metaphors, and multiple meanings. Then in stage 3, children use their bilingualism to learn additional English, through print in a bilingual, interactive learning mode (Hoffmeister \& Caldwell-Harris, 2014). In this way, a strong foundation in sign language is used as the bridge to becoming bilingual in both sign and a later developed spoken language.

\subsection{Whole to Part (Top down) Approach}

Rather than starting at the word/phrase level as proposed by Hoffmeister and Caldwell-Harris (2014) or focusing on letter knowledge as one indicator of emergent literacy (Allen et al., 2014), a whole-to-part or top down model developed for hearing children was proposed by Mason and her colleagues (Mason, Stewart, Peterman, \& Dunning, 1992; McCormick \& Mason, 1989, 1990) and was adapted for signing deaf children. This model can explain reading picture phrase books (Andrews \& Mason, 1986), reading expository science texts (Andrews \& Mason, 1991) as well as reading fables using ASL summaries (Andrews, Winograd, \& Deville, 1994). According to Mason and her colleagues, children's earliest concepts about print and books are developed from their earliest experiences and interactions with storybook reading, environmental print and writing, as well as their own attempts to read, write, and make meanings from social interactions. Early reading encompasses the awareness and experiences with reading, writing, speaking, listening and thinking, all of which occurred in the home prior to children starting the formal instruction of conventional literacy in the first grade. This view of reading is not only historical, but is still relevant today as researchers studying deaf children continue to use these emergent literacy frameworks (Herbold, 2008; see reviews in Trezek \& Mayer, 2015; Williams, 2004). These recent works show that signing deaf children by age five can identify environmental print, write their names, fingerspell their names, write most, if not all, of the alphabet, and recite back elements of storybooks after being read to (Herbold, 2008; Williams, 2004). This framework includes four components, listed and explained below.

1) Concepts and functions of literacy include knowledge of terms that are used to talk about reading. Here understanding the functions of print, knowing how the act of reading is carried out (i.e. knowing where to begin, and how to continue reading by turning pages), how to separate speech into words, syllables, and letters become the foundations of literacy. Then, being able to track a line of print and one's self-perceptions about reading are important components of becoming a reader. Finally, context-sensitive strategies for word reading and knowledge of environment print in familiar contexts allow the child to become literate. These functions are top-down and provide the big picture about reading.

2) Knowledge of letters and words functions as the bottom-up support for becoming literate. This knowledge includes letter knowledge, phonological awareness of beginning and ending sounds in words, graphemephoneme correspondence knowledge, and word recognition of common words and words containing generalizable patterns.

3) Listening comprehension and word understanding again brings in whole-to-part strategies and includes complete or partial retelling of stories, defining, classifying, drawing analogies to words, and developing multiple strategies for reading texts.

4) Writing and composing moves into the written forms of literacy, focusing on word writing, sentence dictation, and story composition.

Here even though word identification and word decoding are important, the point being made is that early reading is more comprehensive than phonological awareness and vocabulary. By extension to deaf children, early reading does not start at the one sign to one word mapping event, but can be initiated when a whole story or passage is presented in easy-to-read books with pictures, through signing conversations children have with adults, or with short passages of texts.

Using a top-down reading model, as these studies suggest, is supported by research (Supalla, Hauser, \& Bavelier, 2014) in the short-term memory processes of deaf children and deaf adults who are fluent signers. On a recall task using ASL sentences, fluent signers (both children and adults) used top-down scaffolding in their working memory to retrieve the meaning of the ASL sentences. In contrast, deaf signers who were not fluent in sign used more linear strategies and visuospatial memory to imitate signed words. Additionally, they recalled lexical signs in linear order and omitted function words. Given these findings, Andrews and her colleagues suggest that to focus on early reading at the word-sign mapping or fingerspelling/decoding process is to miss the 
larger picture of what real readers do-the reading of complete texts, whether they are language experience stories, simple easy-to-read picture books, or more complex texts.

\subsection{The Five-Component Model}

Another model is based on visual language and visual learning; the theoretical underpinning is based on the literature about multiliteracies and the sociocultural view of literacy (Kuntze, Golos, \& Enns, 2014). This model is an alternative pathway, as reading comprehension is not only based on language acquisition and emergent literacy skills, but also learning a new language (ASL) as part of this process. This early reading model includes five components: ASL acquisition and visual engagement, emergent literacy, social mediation with English print, literacy and Deaf culture, and finally multimedia activities. It also includes the use of indigenous practices by deaf parents within their signing families; these interactions socialize deaf children into becoming readers (Kuntze et al., 2014). Their model suggests that the signing deaf children acquire reading through the visual modality, without access to spoken language, and that reading instruction should reflect these visual ways of learning.

\subsection{ASL Sign Writing}

The last model that uses visual language is one that develops reading instruction by having deaf children learn to read ASL graphemes and ASL glosses. Glossing is a written notation system devised to represent ASL (Supalla \& Cripps, 2011). In the first stages children learn to match pictures of objects with pictures of manual signs. Then deaf children are taught a new writing system, which uses graphemes that represent the visual phonology of signs, including their hand shape, movement and location. In the third stage, children are taught to read English glosses for ASL signs, which is called ASL glossing. Supalla and colleagues use ASL gloss as an intermediary writing system, which links the child's ASL to English print. There is an ASL Resource book, with gloss text written in what the authors call the ASL-phablet. The ASL graphemes are written in a linear string to create sign equivalents of English words (Supalla et al., 2001; Supalla \& Cripps, 2011).

\subsection{Summary}

These visual perspectives are noteworthy because they focus on the language of the Deaf community to bridge meaning to English print without the use of English auditory phonology. Moreover, reading instruction for English here involves using the linguistic structure of ASL to bridge meaning from one language to the other. Not yet available is a strong science base to determine if these top-down models for deaf children are a promising avenue for learning to read. So far these visual models suggest that there is more involved in learning to read than only bottom up strategies based on spoken language teaching curriculums.

We do not dispute the fact that hearing loss exists along a continuum. Ninety-five percent of deaf children have hearing parents. Many deaf children have some residual hearing, which permits access to auditory processing strategies and other auditory cognitive processing strategies to comprehend print, especially if they have cochlear implants or digital hearing aids (Marschark et al., 2015). However, in view of the documented delay of the language and early literacy of young deaf children using auditory methods to teach reading (Cupples et al., 2014), we think that alternative approaches using signs and fingerspelling are warranted, given the accumulating data showing the early sign language acquisition facilitates the development of early reading (Allen, 2015; Clark et al., 2016; Freel et al., 2011; Mayberry et al., 2011; Pénicaud et al., 2013).

As such, the five visual frameworks we present are united in that they suggest that all deaf children can be bilingual, where both ASL and fingerspelling can be used to become literate in English. Furthermore, they support the notion that the rhythmic and statistical regularities of ASL and fingerspelling have a facilitating role, in that it gives deaf children another tool, visual phonology, to use as a bridge to the learning of English (Kuhl \& Rivero-Gaxiola, 2008; Mayberry et al., 2011).

\subsection{Suggestions for an Alternative Paradigm}

These five deafcentric frameworks focus on the visual language of ASL and visual learning, as well as the use of Deaf cultural role models in the teaching of reading. These models warrant consideration in future research because too many deaf children's academic success has not improved for decades (Johnson, Liddell, \& Erting, 
1989; Qi \& Mitchell, 2011). Creating a Fault Tolerant System in the schools and home, as proposed by Treisman (1992, 2013), therefore, would be worth trying.

In developing his ideas, Treisman (1992) was attempting to reverse the failure of African American students in STEM fields (especially calculus) at Berkley. Treiman wanted to understand why different environments lead to success while others lead to failure. He suggests we focus on environments that create Fault Tolerant Systems, where individuals are able to absorb problems and overcome them, rather than succumb to them. These systems promote resiliency and allow community cultural wealth (Yosso, 2005) to protect those from underrepresented groups to succeed. If one looks at this kind of cultural capital, one finds strategies that are taught outside of the dominant culture to permit success.

Deaf capital wealth includes using a visual language, visual learning, and successful Deaf adult role models-leading to aspirational capital, which serves as a protective factor in the face of lower expectations from hearing members of the society (Twitchell, Morford, \& Hauser, 2015). Some researchers have already incorporated visual language, visual learning and Deaf cultural role models, as in the five models discussed above, and others include visual language in the teaching of early reading (Humphries, 2004; Humphries et al., 2014).

Can the Triesman model lead us to a new perspective related to deaf children and their literacy and language development? As we know young deaf children are experiencing the same overall levels of failure (Allen, 1986; Marschark \& Harris, 1996; Musselman, 2000) as those African American students who were Treisman's focus. What might Treisman have to contribute to this evolution in deaf education from the current model to a "fault tolerant" system?

Treisman (1992) states that there are unequal opportunities to learn and therefore, one needs to develop "magic bullet" interventions where people can "suspend belief" about failure. We can create expectations and positive mindsets to allow us to instill survival skills. We need to design educational environments where we search for those who are not well served and understand the factors that prohibit self-efficaciousness in families, teachers, and students. One must have a universally connected system of support for it to be fault tolerant (Treisman, 2013). Here early interventions with deaf infants, as well as effective deaf education, qualify as a system that would benefit from a re-design.

Parents could create another system; this system would include a deaf infant whose parents were taught how to develop and maintain eye gaze with their infant to develop strong attachment and reciprocal turn-taking (Clark et al., 2015). Turn-taking is crucial as it underlies both social and language development and sets the stage for future learning between teachers and students. Applying this model, medical and early intervention professionals would strongly suspect that these hearing parents would be unaware of how their own attention getting devices would not be effective with their deaf and hard of hearing infant. Their goals would be for parents and their infant to have a strong start and learn how to regulate attention for later social-emotional, linguistic, and future learning interactions. The focus might be on attention, rather than focusing on discussing a choice between signed or spoken language. The goal for this discussion would be to be sure that parents had a mechanism that allowed them to develop strong caregiver-infant bonds. The parents and child could later decide on the best strategies for language choice, school choice, and how to have strong peer relationships for their deaf and hard of hearing child.

Medical professionals, audiologists, early childhood educators, schools, and families, would work to be sure that the deaf and hard of hearing child was developing according to well-known linguistic, social-emotional, behavioral, and academic milestones. The focus would be on visual language; i.e., being sure to allow the child to look for language, regardless if it was spoken or signed (Clark et al., 2015). This system would monitor the child's ongoing development, based on evidence-based practices in developmental psychology. The system would be sure to provide all options to the family and the deaf and hard of hearing child, including research about how early signing with cochlear implants does not negatively impact spoken language development (Hassanzadeh, 2012; Lyness, Woll, Campbell, \& Cardin, 2013). These professionals would recommend the best of all hearing technologies, language possibilities, and all possible educational options. The societal system would place the deaf and hard of hearing child in an environment that embraced differences and established a cultural perspective that focused on diversity and how all can contribute to the success of our world.

\subsection{Personal Reflections}

As a bilingual team of two hearing and two deaf authors, we have experienced alternative outcomes, following 
the developmental model of Triemsan, proposed above. Kim Misener Dunn, one of our collaborators, who is Deaf, commented on how her early home and preschool experiences, most notably parent home conversations and early book reading "had a profound impact on my vocabulary development." She elaborated below:

My preschool teacher encouraged my parents and siblings to read me books with printed sign language. Because of my early access to a visual literacy environment, I was reading when I entered kindergarten at age four. I used print labeling in the home and sign language to teach my hearing daughter how to read, and it was successful.

Beth Hamilton, our second collaborator, who is Deaf, had a different family system than Kim Misener Dunn and was exposed to signed vocabulary at age $31 / 2$ years. She was born prelingually and profoundly deaf. Beth Hamilton emphasized the importance of early signing and sibling support.

I started formal school at age $31 / 2$, and my vocabulary and language thrived. I remembered how I first learned to read in kindergarten when my teacher connected ASL-story telling, picture and words. Now that I have a deaf preschool daughter, I use the same strategies with her.

It is evident that we see systems that were aware of appropriate language development. The larger societal systems provided alternative strategies to allow effective development of cognitive academic language proficiency (CALP) (Cummins, 1979). When the environments were adapted for visual learners, this change permitted both deaf authors to succeed academically and enter doctoral level programs to improve the educational systems of other deaf children.

\section{Conclusion}

If we consider early reading and deaf children within the context of the development of the whole child, we can see that they need a strong language base for communication, thinking, and learning. Speech skills are not sufficient. Visual communication, such as signing could support the development of the children's delayed speech. Clearly, the environment must be assessed to determine if it is supporting the child's needs. The model would emphasize that a deaf hearing status is simply a difference and not a deficit. Models of deficiency should be replaced with developmental models that monitor the development of executive functioning, linguistic development, and socio-emotional development, which will become the foundations for later academic learning and success. Many young deaf children of hearing parents (Karchmer \& Mitchell, 2003) from non-signing homes have not yet developed BICS, or basic interpersonal communication skills (Cummins, 1979), leaving them without the linguistic foundation to enter school and build CALP. Developmental monitoring to evaluate known linguistic milestones could have sent up warning flags that would have allowed modifications of early interventions to prevent or reduce these multi-year linguistic delays.

Given the continuing failure of our deaf educational system for many deaf children, if we analyze the systems involved in this result, we would expect much higher levels of performance given recent research in bimodal/ bilingual and bilingual language approaches for deaf children (Allen, 2015; Mayberry \& Eichen, 1991; Mayberry et al., 2002; Petitto, 2009; Petitto \& Marentette, 1991; Petitto et al., 2012). Given the language and literacy delays typically noted in the literature, it appears to be time to consider a paradigm shift in the sense of Kuhn (2012). This suggestion is not to reject hearing technologies, nor reject the phonological orientation. Auditory phonological training may be of use to the deaf child in conjunction with other strategies at different times during their reading instructional lives, particularly after a solid language base has been established visually. The visual language orientation is more comprehensive and can provide young deaf infants with an early bimodal/ bilingual or bilingual intervention. This type of intervention can maximize both their access to spoken as well as visual language for a more effective outcome by age five; the time at which most children enter kindergarten to learn more about reading. Given the evidence of multiple pathways for learning to read, our Fault Tolerant System would closely monitor ongoing developmental trajectories and modify and adapt language environments and educational systems as needed.

This Fault Tolerant System would embrace several philosophies. First, it would use critical pedagogy as the baseline for linguistic and academic success; failure would be attributed to ineffective systems and not to deficits in deaf children. Next, the Fault Tolerant System would adjust ecological niches to allow for multiple pathways to linguistic development and academic success. Finally, deaf and hearing partnerships would be the norm in all research, policy, and educational decision-making situations. Since Unlocking the Curriculum (Johnson et al., 1989), deaf education has failed to modify the academic success for the majority of deaf children and has not 
eliminated the cycle of low expectation often found in our medical and educational systems. The 12 principles found in the work of Johnson et al. in conjunction with more recent work on bimodal bilingualism (Nussbaum, Scott, \& Simms, 2012) in combination with these suggestions for a Fault Tolerant System, just MAY improve deaf education. What do we have to lose: a large percentage of another generation of deaf children, which is not acceptable.

\section{References}

Allen, T. (1986). Patterns of Academic Achievement among Hearing Impaired Students: 1974 and 1983. In A. N. Schildroth, \& M. A. Karchmer (Eds.), Deaf Children in America (pp. 161-206). San Diego, CA: College-Hill Press.

Allen, T. E., Letteri, A., Choi, S. H., \& Dang, D. (2014). Early Visual Language Exposure and Emergent Literacy in Preschool Deaf Children: Findings from a National Longitudinal Study. American Annals of the Deaf, 159, 346-358. http://dx.doi.org/10.1353/aad.2014.0030

Allen, T. E. (2015). ASL Skills, Fingerspelling Ability, Home Communication Context and Early Alphabetic Knowledge of Preschool-Aged Deaf Children. Sign Language Studies, 15, 233-265. http://dx.doi.org/10.1353/sls.2015.0006

Andrews, J. F. (2012). Reading to Deaf Children Who Sign: A Response to Williams (2012) and Suggestions for Future Research. American Annals of the Deaf, 157, 307-319. http://dx.doi.org/10.1353/aad.2012.1622

Andrews, J. F., \& Mason, J. M. (1986). How Do Deaf Children Learn about Prereading? American Annals of the Deaf, 131, 210-217. http://dx.doi.org/10.1353/aad.2012.0802

Andrews, J. F., \& Mason, J. M. (1991). Strategy Use among Deaf and Hearing Readers. Exceptional Children, 57, 536-545.

Andrews, J. F., \& Zmijewski, G. (1997). How Parents Support Home Literacy with Deaf Children. Early Child Development and Care, 127, 131-139. http://dx.doi.org/10.1080/0300443971270111

Andrews, J. F., Winograd, P., \& DeVille, G. (1994). Deaf Children Reading Fables: Using ASL Summaries to Improve Reading Comprehension. American Annals of the Deaf, 139, 378-386. http://dx.doi.org/10.1353/aad.2012.0303

Andrews, J., Leigh, I., \& Weiner, M. (2004). Deaf People: Evolving Perspectives in Psychology, Education, and Sociology. Boston, MA: Allyn \& Bacon.

Bailes, C. N., Erting, C. J., Erting, L. C., \& Thumann-Prezioso, C. (2009). Language and Literacy Acquisition through Parental Mediation in American Sign Language. Sign Language Studies, 9, 417-456. http://dx.doi.org/10.1353/sls.0.0022

Baker, S. (2011). Advantages of Early Visual Language. Available from the Visual Language \& Visual Learning website. http://vl2.gallaudet.edu/assets/section7/document104.pdf

Berke, M. (2013). Reading Books with Young Deaf Children: Strategies for Mediating between American Sign Language and English. Journal of Deaf Studies and Deaf Education, 18, 299-311. http://dx.doi.org/10.1093/deafed/ent001

Clark, M. D., Galloza, A., Keith, C. L., Tibbitt, J. S., Wolsey, J. A., \& Zimmerman, H. G. (4 May 2015). Eye Gaze: Learning to Look and Looking to Learn. ADVANCE for Speech and Hearing. http://speech-language-pathology-audiology.advanceweb.com/Features/Articles/Eye-Gaze-Development-in-Infants.aspx

Clark, M. D., Gilbert, G., \& Anderson, M. L. (2011) Morphological Knowledge and Decoding Skills of Deaf Readers. Psychology, 2, 109-116. http://dx.doi.org/10.4236/psych.2011.22018

Clark, M. D., Hauser, P., Miller, P., Kargin, T., Rathmann, C., Guidenoglu, B., Kubus, O., Spurgeon, E., \& Israel, E. (2016). The Importance of Early Sign Language Acquisition for Deaf Readers. Reading \& Writing Quarterly: Overcoming Learning Difficulties, 32, 127-151. http://dx.doi.org/10.1080/10573569.2013.878123

Convertino, C., Borgna, G., Marschark, M., \& Durkin, A. (2014). Word and World Knowledge among Deaf Earners with and without Cochlear Implants. Journal of Deaf Studies \& Deaf Education, 19, 471-483.

http://dx.doi.org/10.1093/deafed/enu024

Cornett, O. (1967). Cued Speech. American Annals of the Deaf, 112, 3-13.

Cummins, J. (1979). Linguistic Interdependence and the Educational Development of Bilingual Children. Review of Educational Research, 49, 222-251. http://dx.doi.org/10.3102/00346543049002222

Cupples, L., Ching, T. Y. C., Crowe, K., Day, J., \& Seeto, M. (2014). Predictors of Early Reading Skill in 5-Year-Old Children with Hearing Loss Who Use Spoken Language. Reading Research Quarterly, 49, 85-104.

Easterbrooks, S. R., Lederberg, A. R., Antia, S., Schick, B., Kushnalnagar, P., Webb, M.-Y., \& Connor, C. M. (2015). Reading among Diverse DHH Learners: What, How, and for Whom? American Annals of the Deaf, 159, 419-432. http://dx.doi.org/10.1353/aad.2015.0002

Freel, B. L. Clark, M. D., Anderson, M. L., Gilbert, G., Musyoka, M. M., \& Hauser, P. C. (2011). Deaf Individuals’ Bilingual Abilities: American Sign Language Proficiency, Reading Skills, and Family Characteristics. Psychology, 2, 18-23. http://dx.doi.org/10.4236/psych.2011.21003 
Geers, A. E., \& Hayes, H. (2011). Reading, Writing, and Phonological Processing Skills of Adosescents with 10 or More Years of Cochlear Implant Experience. Ear and Hearing, 32, 49S-59S. http://dx.doi.org/10.1097/AUD.0b013e3181fa41fa

Goldin-Meadow, S., \& Mayberry, R. I. (2001). How Do Profoundly Deaf Children Learn to Read? Learning Disabilities Research \& Practice, 16, 222-229. http://dx.doi.org/10.1111/0938-8982.00022

Gough, P. B., \& Tunmer, W. E. (1986). Decoding, Reading, and Reading Disability. Remedial and Special Education, 7 , 6-10. http://dx.doi.org/10.1177/074193258600700104

Hassanzadeh, S. (2012). Outcomes of Cochlear Implantation in Deaf Children of Deaf Parents: Comparative Study. Journal of Laryngology and Otology, 126, 989-994. http://dx.doi.org/10.1017/S0022215112001909

Herbold, J. (2008). Emergent Literacy Development: Case Studies of Four Deaf ASL-English Bilinguals. Unpublished Doctoral Dissertation, Tucson, AZ: University of Arizona.

Hirshorn, E. A. (2011). Exploring Alternate Routes to Literacy in Profoundly Deaf Individuals. Doctoral Dissertation, Rochester, NY: University of Rochester.

Hoffmeister, R. J., \& Caldwell-Harris, C. L. (2014). Acquiring English as a Second Language via Print: The Task for Deaf Children. Cognition, 132, 229-242. http://dx.doi.org/10.1016/j.cognition.2014.03.014

Humphries, T. (2004). The modern Deaf Self: Indigenous Practices and Educational Imperatives. In B. J. Brueggeman (Ed.), Literacy and Deaf People: Cultural and Contextual Perspectives (pp. 29-46). Washington DC: Gallaudet University Press.

Humphries, T., Kushalnagar, P., Mathur, G., Napoli, D. J., Padden, C., \& Rathmann, C. (2014). Ensuring Language Acquisition for Deaf Children: What Linguists Can Do. Language, 90, e31-e52.

http://dx.doi.org/10.1353/lan.2014.0036

Johnson, C., \& Goswami, U. (2010). Phonological Awareness, Vocabulary, and Reading in Deaf Children with Cochlear Implants. Journal of Speech, Language, and Hearing Research, 53, 237-261. http://dx.doi.org/10.1044/1092-4388(2009/08-0139)

Johnson, R. E., Liddell, S. K., \& Erting, C. J. (1989). Unlocking the Curriculum: Principles for Achieving Access in Deaf Education. Working Paper 89-3.

Karchmer, M. A., \& Mitchell, R. E. (2003). Demographic and Achievement Characteristics of Deaf and Hard-of-Hearing Students. In M. Marschark, \& P. E. Spencer (Eds.), Oxford Handbook of Deaf Studies, Language, and Education (pp. 21-37). New York: Oxford University Press.

Kelly, L. (1996). The Interaction of Syntactic Competence and Vocabulary during Reading by Deaf Students. Journal of Deaf Studies and Deaf Education, 1, 75-90. http://dx.doi.org/10.1093/oxfordjournals.deafed.a014283

Kuhl, P., \& Rivera-Gaxiola, M. (2008). Neural Substrates of Language Acquisition. Annual Review of Neuroscience, 31, 511-534. http://dx.doi.org/10.1146/annurev.neuro.30.051606.094321

Kuhn, T. S. (2012). The Structure of Scientific Revolutions. Chicago, IL: University of Chicago Press. http://dx.doi.org/10.7208/chicago/9780226458144.001.0001

Kuntze, L., Golos, D., \& Enns, C. (2014). Rethinking Literacy: Broadening Opportunities for Visual Learners. Sign Language Studies, 14, 203-224. http://dx.doi.org/10.1353/sls.2014.0002

Kushalnagar, P., Mathur, G., Moreland, C. J., Napoli, D. J., Osterling, W., Padden, C., \& Rathmann, C. (2010). Infants and Children with Hearing Loss Need Early Language Access. The Journal of Clinical Ethics, 21, 143.

Lartz, M. N. (1999). Teaching Hearing Parents to Read Effectively to Their Children Who Are Deaf. Teaching Exceptional Children, 31, 43-46. http://dx.doi.org/10.1177/004005999903100507

LaSasso, C. J., \& Crain, K. L. (2015). Reading for Deaf and Hearing Readers: Qualitatively and/or Quantitatively Similar or Different? A Nature versus Nurture Issue. American Annals of the Deaf, 159, 447-467. http://dx.doi.org/10.1353/aad.2015.0004

Lieberman, A. M., Hatrak, M., \& Mayberry, R. I. (2011). The Development of Eye Gaze Control for Linguistic Input in Deaf Children. In N. Danis, K. Mesh, \& H. Sung (Eds.), Proceedings of the 35th Boston University Conference on Language Development (pp. 391-403). Somerville, MA: Cascadilla Press.

Liu, H. T., Liu, C. J., \& Andrews, J. F. (2014). Literacy and Deaf Students in Taiwan: Issues, Practices and Directions for Future Research: Part I. Deafness \& Education International, 16, 2-22. http://dx.doi.org/10.1179/1464315413Z.00000000055

Luckner, J. L., Sebald, A. M., Cooney, J., Young, J., \& Muir, S. G. (2005). An Examination of the Evidence-Based Literacy Research in Deaf Education. American Annals of the Deaf, 150, 443-456. http://dx.doi.org/10.1353/aad.2006.0008

Lyness, C. R., Woll, B., Campbell, R., \& Cardin, V. (2013). How Does Visual Language Affect Crossmodal Plasticity and Cochlear Implant Success? Neuroscience \& Biobehavioral Reviews, 37, 2621-2630.

http://dx.doi.org/10.1016/j.neubiorev.2013.08.011 
Marschark, M., \& Everhart, V. S. (1997). Relations of Language and Cognition: What Do Deaf Children Tell Us. In M. Marschark, P. Siple, D. Lillo-Martin, R. Campbell, \& V. S. Everhart (Eds.), Relations of Language and Thought: The View from Sign Language and Deaf Children (pp. 3-23). New York, NY: Oxford University Press.

Marschark, M., Spencer, L. J., Durkin, A., Borgna, G., Convertino, C., Machmer, E., Kronenberger, W. G., \&Trani, A. (2015). Understanding Language, Hearing Status, and Visual-Spatial Skills. Journal of Deaf Studies and Deaf Education, 20, 310-330. http://dx.doi.org/10.1093/deafed/env025

Marschark, M., \& Harris, M. (1996). Success and Failure in Learning to Read: The Special Case (?) of Deaf Children. In C. Cornoldi, \& J. Oakhill (Eds.), Reading Comprehension Difficulties: Processes and Intervention (pp. 279-300). Mahwah, NJ: Lawrence Earlbaum and Associates.

Mason, J. (1980). When Do Children Begin to Read: An Exploration of Four-Year-Old Children’s Letter and Word Reading Competencies. Reading Research Quarterly, 15, 203-227. http://dx.doi.org/10.2307/747325

Mason, J. (1990). Reading Stories to Preliterate Children: A Proposed Connection to Reading (Chapter 8). In P. Gough, L. Ehri, \& R. Treiman (Eds.), Reading Acquisition. Hillsdale, NJ: Erlbaum Associates.

Mason, J., Stewart, J., Peterman, C., \& Dunning, D. (1992). Toward an Integrated Model of Early Reading Development, Technical Report No. 566. Champaign, IL: Center for the Study of Reading.

Mayberry, R. I., \& Eichen, E. B. (1991). The Long-Lasting Advantage of Learning Sign Language in Childhood: Another Look at the Critical Period for Language Acquisition. Journal of Memory and Language, 30, 486-512. http://dx.doi.org/10.1016/0749-596X(91)90018-F

Mayberry, R. I., Chen, J. K., Witcher, P., \& Klein, D. (2011). Age of Acquisition Effects on the Functional Organization of Language in the Adult Brain. Brain and Language, 119, 16-29. http://dx.doi.org/10.1016/j.bandl.2011.05.007

Mayberry, R. I., Del Giudice, A. A., \& Lieberman, A. M. (2011). Reading Achievement in Relation to Phonological Coding and Awareness in Deaf Readers: A Meta-Analysis. Journal of Deaf Studies and Deaf Education, 16, 164-188. http://dx.doi.org/10.1093/deafed/enq049

Mayberry, R. I., Lock, E., \& Kazmi, H. (2002). Development: Linguistic Ability and Early Language Exposure. Nature, 417, 38-38. http://dx.doi.org/10.1038/417038a

McCormick, C., \& Mason, J. (1990). Little Books. Chicago, IL: Scott Foresman.

McCormick, C., \& Mason, J. M. (1989). Fostering Reading for Head Start Children with Little Books. In J. Allen, \& J. M. Mason (Eds.), Risk Makers, Risk Takers, Risk Breakers: Reducing the Risks for Young Literacy Learners (pp. 154-177). Portsmouth, NH: Heinemann.

McQuarrie, L., \& Parrila, R. (2014). Literacy and Linguistic Development in Bilingual Deaf Children: Implications of the “and” for Phonological Processing. American Annals of the Deaf, 159, 372-384. http://dx.doi.org/10.1353/aad.2014.0034

Miller, P., \& Clark, M. D. (2011). Phonemic Awareness Is Not Necessary to Become a Skilled Deaf Reader. Journal of Developmental and Physical Disabilities, 23, 459-476. http://dx.doi.org/10.1007/s10882-011-9246-0

Montag, J. L., AuBuchon, A. M., Pisoni, D. B., \& Kronenberger, W. G. (2014). Speech Intelligibility in Deaf Children after Long-Term Cochlear Implant Use. Journal of Speech, Language, and Hearing Research, 57, 2332-2343. http://dx.doi.org/10.1044/2014_JSLHR-H-14-0190

Musselman, C. (2000). How Do Children Who Can’t Hear Learn to Read an Alphabetic Script? A Review of the Literature on Reading and Deafness. Journal of Deaf Studies and Deaf Education, 5, 9-31. http://dx.doi.org/10.1093/deafed/5.1.9

Nielsen, D. C., Luetke, B., \& Stryker, D. S. (2011). The Importance of Morphemic Awareness to Reading Achievement and the Potential of Signing Morphemes to Supporting Reading Development. Journal of Deaf Studies and Deaf Education, 16, 275-288. http://dx.doi.org/10.1093/deafed/enq063

Nunes, T., \& Bryant, P. (2006). Improving Literacy by Teaching Morphemes. New York: Routledge.

Nussbaum, D. B., Scott, S., \& Simms, L. E. (2012). The “Why” and “How” of an ASL/English Bimodal Bilingual Program. Odyssey: New Directions in Deaf Education, 13, 14-19.

Paul, P. V. (2013). The View from the Edge: Rethinking a Few Ideas. American Annals of the Deaf, 158, 287-291. http://dx.doi.org/10.1353/aad.2013.0025

Paul, P. V., \& Wang, Y. (2012). Literate Thought: Understanding Comprehension and Literacy. Sudbury, MA: Jones \& Bartlett Learning.

Paul, P. V., Wang, Y., Trezek, B. J., \& Luckner, J. L. (2009). Phonology Is Necessary, but Not Sufficient: A Rejoinder. American Annals of the Deaf, 154, 346-356. http://dx.doi.org/10.1353/aad.0.0110

Payne, J. A., \& Quigley, S. (1987). Hearing-Impaired Children’s Comprehension of Verb-Particle Combinations. The Volta Review, 89, 133-143.

Pénicaud, S., Klein, D., Zatorre, R. J., Chen, J. K., Witcher, P., Hyde, K., \& Mayberry, R. I. (2013). Structural Brain 
Changes Linked to Delayed First Language Acquisition in Congenitally Deaf Individuals. NeuroImage, 66, 42-49. http://dx.doi.org/10.1016/j.neuroimage.2012.09.076

Petitto, L. A. (2009). New Discoveries from the Bilingual Brain and Mind across the Life Span: Implications for Education. Mind, Brain, and Education, 3, 185-197. http://dx.doi.org/10.1111/j.1751-228X.2009.01069.x

Petitto, L. A., \& Marentette, P. F. (1991). Babbling in the Manual Mode: Evidence for the Ontogeny of Language. Science, 251, 1493-1496. http://dx.doi.org/10.1126/science.2006424

Petitto, L. A., Berens, M. S., Kovelman, I., Dubins, M. H., Jasinska, K., \& Shalinsky, M. (2012). The "Perceptual Wedge Hypothesis” as the Basis for Bilingual Babies’ Phonetic Processing Advantage: New Insights from fNIRS Brain Imaging. Brain and Language, 121, 130-143. http://dx.doi.org/10.1016/j.bandl.2011.05.003

Qi, S., \& Mitchell, R. E. (2011). Large-Scale Academic Achievement Testing of Deaf and Hard-of-Hearing Students: Past, Present, and Future. Journal of Deaf Studies and Deaf Education, enr028.

Rittenhouse, R. K., \& Stearns, K. (1990). Figurative Language and Reading Comprehension in American Deaf and Hard of-Hearing Children: Textual Interactions. International Journal of Language \& Communication Disorders, 25, 369-374. http://dx.doi.org/10.3109/13682829009011984

Seifert, E., Oswald, M., Bruns, U., Vischer, M., Kompis, M., \& Haeusler, R. (2002). Changes of Voice and Articulation in Children with Cochlear Implants. International Journal of Pediatric Otorhinolaryngology, 66, 115-123. http://dx.doi.org/10.1016/S0165-5876(02)00216-1

Stanovich, K. E. (2000). Progress in Understanding Reading: Scientific Foundations and New Frontiers. New York: Guilford Press.

Sugiura, Y. (2012). A Description of Young Deaf Children's Comprehension of English Punctuation when Reading Comics. Doctoral Dissertation, Beaumont, TX: Lamar University.

Supalla, S. J., Wix, T. R., \& McKee, C. (2001). Print as a Primary Source of English for Deaf Learners. In J. Nicol (Ed.), One Mind, Two Languages: Studies in Bilingual Language Processing (pp. 77-190). New York: Wiley-Blackwell.

Supalla, S. J., \& Cripps, J. H. (2011). Toward universal design in reading instruction. Bilingual Basics, 12, 1-13.

Supalla, T., Hauser, P. C., \& Bavelier, D. (2014). Reproducing American Sign Language Sentences: Cognitive Scaffolding in Working Memory. Frontiers in Psychology, 5, 859. http://dx.doi.org/10.3389/fpsyg.2014.00859

Traxler, C. B. (2000). The Stanford Achievement Test: National Norming and Performance Standards for Deaf and Hard-ofHearing Students. Journal of Deaf Studies and Deaf Education, 5, 337-348. http://dx.doi.org/10.1093/deafed/5.4.337

Treisman, P. U. (2013). Leveraging Knowledge from Developmental Sciences for Improving Modern STEM Education. Invited address presented at the Biannual Meeting of the Society for Research in Child Development, Seattle, April 2013.

Treisman, U. (1992). Studying Students Studying Calculus: A Look at the Lives of Minority Mathematics Students in College. College Mathematics Journal, 23, 362-372. http://dx.doi.org/10.2307/2686410

Trezek, B. J., \& Mayer, C. (2015). Using an Informal Reading Inventory to Differentiate Instruction: Case Studies of Three Deaf Learners. American Annals of the Deaf, 160, 289-302. http://dx.doi.org/10.1353/aad.2015.0025

Twitchell, P., Morford, J. P., \& Hauser, P. C. (2015). Effects of SES on Literacy Development of Deaf Signing Bilinguals. American Annals of the Deaf, 159, 433-446. http://dx.doi.org/10.1353/aad.2015.0003

Wang, Y., Lee, C., \& Paul, P. V. (2010). An Understanding of the Literacy Levels of Students Who Are Deaf/Hard-ofHearing in the United States, China, and South Korea. Educational Studies in Language and Literature, 10, 87-98.

Watson, L., \& Swanwick, R. (2008). Parents' and Teachers’ Views on Deaf Children's Literacy at Home: Do They Agree? Deafness \& Education International, 10, 22-39. http://dx.doi.org/10.1179/146431508790559896

Williams, C. (2004). Emergent Literacy of Deaf Children. Journal of Deaf Studies and Deaf Education, 9, 352-365. http://dx.doi.org/10.1093/deafed/enh045

Yosso, T. J. (2005). Whose Culture Has Capital? A Critical Race Theory Discussion of Community Cultural Wealth. Race Ethnicity and Education, 8, 69-91. http://dx.doi.org/10.1080/1361332052000341006 